\title{
Farklı Yetiştirme Ortamlarının Oriental Lilium 'Siberia' Çeşidinde Çiçek Kalitesi ve Soğan Verimi Üzerine Etkileri
}

\author{
Ömer Sarı ${ }^{1 *} \quad$ Fisun Gürsel Çelikel ${ }^{2}$ \\ ${ }^{1}$ Karadeniz Tarımsal Araştırma Enstitüsü, Samsun \\ ${ }^{2}$ Ondokuz Mayıs Üniversitesi, Ziraat Fakültesi, Bahçe Bitkileri Bölümü, Samsun \\ Geliş tarihi (Received): 30.05.2017Kabul tarihi (Accepted): 15.09.2017
}

\section{Anahtar kelimeler: \\ Oriental Lilium 'Siberia', kesme çiçek, yetiştirme ortamı, sera}

*Sorumlu yazar

omer.sari@tarim.gov.tr

\begin{abstract}
Özet. Bu çalışma Oriental Lilium 'Siberia' çeşidinin sera koşullarında farklı yetiştirme ortamları kullanılarak en iyi yetiştirme ortamının belirlenmesi amacıyla yapılımışır. Araştırma Ünye Gıda Tarım ve Hayvancılık Illçe Müdürlüğü Uygulama serasında 2013 yaz ve sonbahar döneminde gerçekleştirilmiştir. Yetiştirme ortamı olarak toprak, torf, kum, perlit ve koyun gübresinin (toprak, toprak+torf,perlit, perlit + torf, torf + kum, koyun gübresi + kum) 1:1 karışımından elde edilen toplam 6 farklı ortam kullanılmıştır. Deneme tesadüf parselleri deneme desenine göre üç tekrarlı olarak kurulmuş, her parsele 8 soğan dikilmiştir. Araştırmada çiçek sap uzunluğu, çiçek sap çapı, boğum sayısı, yaprak sayısı yaprak uzunluğu, kandil sayısı, kandil uzunluğu, yavru soğan adedi, yavru soğan boyu ve eni incelenmiş̧tir. Çalışma sonucuna göre çiçek sap uzunluğu, yaprak sayısı, kandil uzunluğu, yavru soğan sayısı bakımından en iyi sonuçlar torf+kum ortamından elde edilmiştir. Yetiştirme ortamı yaprak uzunluğu ve yavru soğan boyunu önemli $(P<0.05)$ derecede etkilememiştir. Koyun gübresi+kum ortamı yavru soğan enini artıııken yavru soğan sayısını azaltmıştır. Kullanılan ortamlar arasında torf+kum karışımı genel olarak çiçek kalitesini ve yavru soğan verimini artırmıştır.
\end{abstract}

\section{Effects of Different Growing Medium on Flower Quality and Bulb Yield of Oriental Lilium 'Siberia'}

\footnotetext{
Keywords:

Oriental Lilium 'Siberia', cut flowers, growing medium, greenhouse
} 


\section{GíRiş}

Lilyum bir sap üzerinde çok sayıda (Şekil 1 ve 2) gösterişli renkli çiçekleri ile kesme çiçek olarak serada veya açıkta yetiştirilen önemli bir geofittir. Lilyum soğanı besin maddesi depolayan etli pullardan (değişime uğramış yapraklar) oluşan gerçek bir soğan yapısındadır. Soğan tabanı (basal kısım) üzerinde birleşen pulları saran, diğer çiçek soğanlarında bulunan koruyucu tabaka (tunik) bulunmadığı için beyaz renklidir. Türkiye genelinde lilyum üretimi 2016 yılı verilerine göre üretim alanı 767.9 da ve üretim miktarı ise 13.310.185 adet olarak gerçekleşmiştir (TÜiK 2016). Ordu ve çevresinde kesme çiçek olarak lilyum yetiştiriciliği giderek gelişmektedir (Çelikel 2014). Etilene duyarlı bir çiçek olan lilyum yetiştiriciliğinde yaprak sararması ve çiçek dökümü çiçek ömrünü belirlemektedir (Çelikel et al., 2002).

Oriental grubun melezi olan Oriental Lilium 'Siberia' (Şekil 1,2) kokulu, beyaz ve iri çiçeklidir. Soğanın alt kısmı beyaz üst kısmı ise sarıdır. Soğan boyutu türe, çeşide ve yaşa göre değişir. Soğanın çevresi birinci yılında, 4-7 cm arasında iken, ikinci yılda, $12-16 \mathrm{~cm}$ ve üçüncü yılda $16 \mathrm{~cm}$ 'e ulaşmaktadır. Dikimden itibaren yaklaşık 110 günde çiçek açan Oriental Lilium 'Siberia' yaz aylarında bol güneş ışığında hızlı büyür ve en iyi performansı gösterir. Dikimler iyi drene olmuş tınlı-kumlu topraklarda en iyi sonucu verir. Çiçeklenme döneminde 6 ile 8 adet arasında çiçek oluştururlar ve 90-110 cm'ye kadar boylanabilirler (Johannes 1996).

Süs bitkilerinde topraksız yetiştirme ortamları günümüzde popülerlik kazanmış ve yoğun bir şekilde bu ortamlar ticari üretim amacıyla kesme çiçek sektöründe başarı ile kullanılmaktadırlar (Maloupa et al., 1992). Yetiştirme ortamında kullanılan materyallerinin farklı karışımlardan (silt, yaprak kompostu, çiftlik gübresi, cocopeat ve perlit) hazırlanması ile ortamların bitkilerin birçok özellikleri üzerine önemli etkilerinin olduğu saptanmaktadır (Hussain et al., 2016). Asyatik zambak hibriti 'America' ve 'Novecento' çeşitlerinin, farklı ortamlarda yetiştiriciliği üzerine yapılan bir çalışmada, kuru madde birikimi ve gövde uzunluklarına bakılmış, en iyi sonucun toprak ve pirinç kavuzu karışımını içeren ortam ile nehir kumu ve perlit karışımından elde edildiği bildirilmiştir (Klasman et al., 2002). Tehranifar et al. (2011) Lilyumun iki tipinin (Asiatik ve Oriental hibridlerinin çeşitleri 'Gronde' ve 'Cassandra') büyüme ve gelişimi üzerine, üç farklı topraksız (cocopeat, çakıl, kum, torf ve perlit) ortamdan elde edilen karışımların etkilerini araştırmışlardır. Çiçek sapı uzunluğu, yaprak sayısı, çiçek sayısı, çiçek çapı, çiçeklenme zamanı, vazo ömrü ve yaprak klorofil içeriği ölçülmüştür. Yetiştirme ortamı sadece çiçek sap boyunu önemli derecede etkilemiştir (Tehranifar et al., 2011). Treder (2008) Oriental Lilium da yaptığı çalışmada erkencilik, kalite, çiçek ve yaprakların yaş ve kuru ağılıkları, kök uzunlukları, kök sayısı ve tomurcuk uzunluğu bakımından bakımından en iyi sonuçların cocopeat ortamından elde edildiğini bildirilmiştir. Okanlawon et al. (2016) toprağın üst tabakası, tavuk gübresi, nehir kumu ve talaş gibi büyüme ortamlarının Mussaenda philippica'nın gelişimi üzerine, toprağın üst tabakası+talaş+tavuk gübresinin karışımının etkisinin diğer ortamlara göre daha iyi olduğunu belirlemişlerdir. Saygılı (2012) tarafından Lilium LA hibrid 'Ceb Dazzle' çeşidinde yapılan ortam denemesinde kestane kabuğu, perlit, yerfıstığı kabuğu, kum, bahçe toprağı, ahır gübresi, torf, hindistan cevizi kabuğu, curuf olmak üzere 9 farklı ortam kullanılmıştır. Çalışmada, bitki gelişimi üzerine etki bakımından, perlit+yerfıstığı kabuğu (1:1) karışımından en iyi sonuçların elde edildiği belirlenmiştir. Yılmaz ve Korkut (1998) 'Connecticut King' kültür çeşidinde 5 farklı (funda toprağı, ibreli toprak, perlit ve tarla toprağı) yetiştirme ortamının çiçeklenme ve çiçek kalitesi üzerine etkilerini inceledikleri araştırmada sürgün verme ve başaklanma süreleri bakımından; 1:1:1 tarla toprağı+perlit+ibreli toprak ve 1:1 funda toprağı+ibreli toprak harçlarında yetiştirilen bitkiler en erkenci olmuştur. En uzun bitki boyu ve en fazla kandil sayısı 1:1 oranında funda toprağı ve ibreli toprak karışımından elde edilmiştir. Yetiştirme harçlarında tarla toprağı oranı arttıkça, bitkilerin çiçeklenme ve çiçek kalitesinde düşme olmuştur.

Farklı araştırıcılar tarafından değişik tür ve çeşitlerde yürütülen çalışmalarda farklı yetiştirme ortamlarının çiçek kalitesini ve verimi önemli derecede etkilediği ortaya çıkmıştır. Ordu ve çevresinde lilyum (zambak) yetiştiriciliği giderek gelişmektedir. Bu nedenle bu çalışmada Ünye şartlarında Oriental Lilium 'Siberia' çeşidinde serada yapılan kesme çiçek yetiştiriciliğinde kolay ulaşılabilir ve düşük maliyetli alternatif yetiştirme ortamlarının kullanım olanaklarının araştırıması ve ortamların çiçek kalitesine ve yavru soğan verimine etkilerinin saptanması amaçlanmıştır.

\section{MATERYAL VE METOT}

Bu araştırma, Ünye Gıda Tarım ve Hayvancılık İlçe Müdürlüğü uygulama serasında (plastik, polietilen örtülü) yaz ve sonbahar yetiştirme döneminde 
yapılmıştır.

Araştırmada kesme çiçek yetiştiriciliği amacıyla ithal edilen Oriental Lilium 'Siberia' çeşidi kullanılmıştır. Oriental Lilium 'Siberia' soğanları çiçek soğanı ithalatı yapan özel bir firmadan temin edilmiştir. Dikim öncesi hastalıklı, yaralanmış, buruşmuş ve sağlıksız soğanlar ayıklandıktan sonra soğanlar çuval içinde \%1(a/h) Captan içeren solüsyonda 30 dakika bekletilmiştir. Daha sonra soğanlar serin gölge bir yerde plastik kasalarda kurumaları için bekletilmiştir.

Dikim işlemi 10 Haziran tarihinde kasalara (Şekil 1) yapılmıştır. Denemede soğanların dikiminde yan ve alt bölümlerinden delikli, geçirimli, $52 \times 36.5 \times 31 \mathrm{~cm}$ ebatlarında 60 litrelik plastik kasalar kullanılmıştır. Kasaların iç kısımları siyah plastik malç örtüsü ile kaplanmıştır. Deneme kasalarının yarısı ortam ile doldurulduktan sonra her kasaya 8 adet soğan eşit aralıklarla yerleştirilmiş (Şekil 1), daha sonra çiçek soğanlarının üzerleri yetiştirme ortamı ile kapatılmıştır.

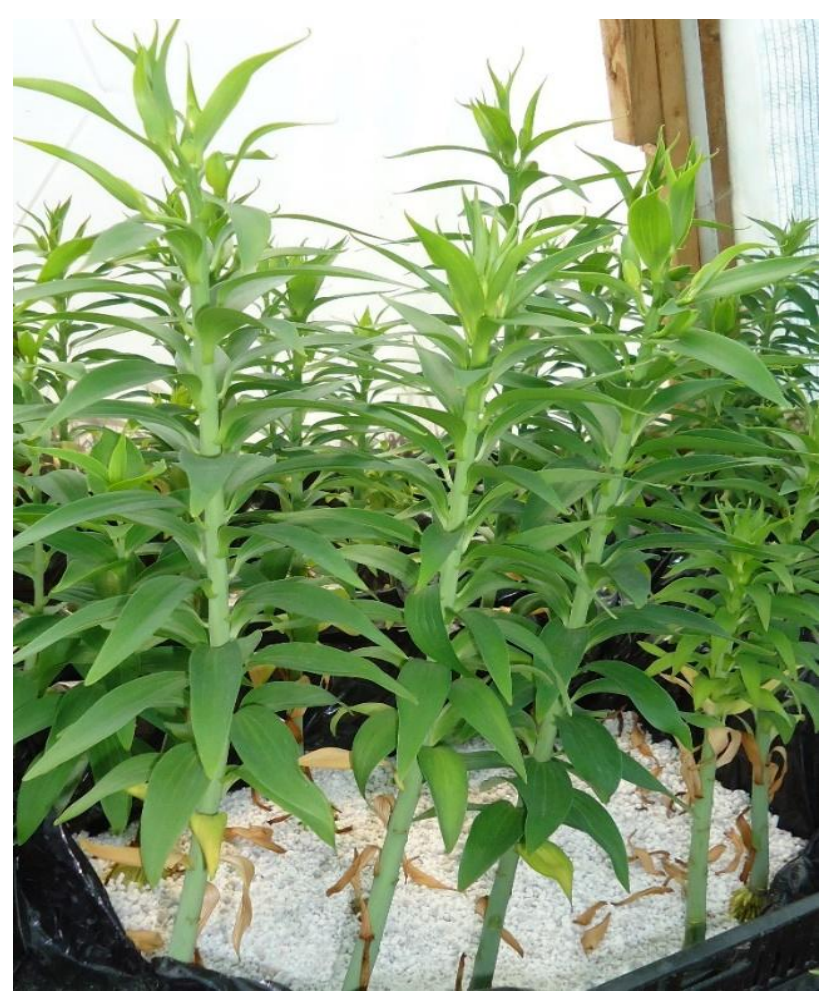

Şekil 1. Oriental Lilium 'Siberia' çeşidinde yetiştirme ortamı denemelerinden bir görünüm.

Figure 1. A view from growing medium experiments on Oriental Lilium 'Siberia'.

Çalışmada toprak (killi bahçe toprağı), torf (0-6 mm, $\mathrm{PH}:$ 5.5-6.5 ve $\left.0.6 \mathrm{~kg} \mathrm{NPK} \mathrm{m}^{-3}\right)$, perlit (0.2-0.5 mm), kum ve koyun gübresinden elde edilen 6 adet ortam oluşturulmuştur (Çizelge 1).
Çizelge 1. Deneme faktörü olarak 6 farklı yetiştirme ortamı kullanılmıştır.

Table 1. Six different growing media were used as trial factor.

\begin{tabular}{clc}
\hline & Yetiştirme ortamları & Karışım oranları \\
\hline 1 & Toprak (kontrol) & 1 \\
2 & Toprak+Torf & $1: 1$ \\
3 & Perlit & 1 \\
4 & Perlit +Torf & $1: 1$ \\
5 & Torf +Kum & $1: 1$ \\
6 & Koyun gübresi+kum & $1: 1$ \\
\hline
\end{tabular}

Bitki besleme uygulamaları ve sulama işlemi doğrudan deneme kasalarına el ile yapılmıştır. Oriental Lilium 'Siberia' soğanlarına dikim zamanından itibaren çıkış yapıncaya kadar sadece su verilmiştir. Çıkışın ardından kütlece (a/a) toplam azot (N) \%10, üre azotu $\left(\mathrm{N}-\mathrm{NH}_{2}\right) \% 10$, suda çözünür fosforpentaoksit $\left(\mathrm{P}_{2} \mathrm{O}_{5}\right)$ \%10, suda çözünür potasyumoksit $\left(\mathrm{K}_{2} \mathrm{O}\right) \quad \% 10$ oranlarında ve iz elementler; suda çözünür bor (B) $\% 0.01$, suda çözünür bakır (Cu) tamamı EDTA ile şelatlı $\% 0.02$, suda çözünür demir (Fe) tamamı EDTA ile şelatlı $\% 0.02$, suda çözünür mangan (Mn) tamamı EDTA ile şelatlı \%0.01, suda çözünür molibden (Mo) \%0.001, suda çözünür çinko ( $\mathrm{Zn}$ ) tamamı EDTA ile şelatlı \%0.002 bileşiminden oluşan makro ve mikro besin elementleri, bitkilerin gübre alımına izin verecek yaprak büyüklüğüne erişmesinden itibaren gelişme dönemi boyunca 10 gün ara ile eritilerek verilmeye başlanmıştır. Kesme çiçeklerin hasadı 11 Kasım 2013 tarihinden itibaren kademeli olarak gerçekleştirilmiştir.

Çalışmada çiçek sap uzunluğu $\mathrm{cm}$ olarak sap ucundan son kandile kadar şerit metre ile ölçülürken, çiçek sap çapı mm olarak sapının ortasından kumpas ile ölçülmüştür. Yaprak sayısı, yaprak uzunluğu cm olarak çiçek sapının orta kısmında yer alan gelişmesini tamamlamış 10 yaprakta, kandil (çiçek tomurcuğu) sayısı adet olarak, kandil uzunluğu $\mathrm{cm}$ olarak, toplam boğum sayısı, çiçeklenme süresi (gün), yavru soğan sayısı, yavru soğan eni ve boyu mm olarak kumpas ile yavru soğanın en geniş yerinden ölçülmüştür.

Çalışma tesadüf parselleri deneme desenine göre 3 tekrarlı olarak kurulmuş, her tekerrürde (kasaya) 8 adet soğan dikilmiştir. Denemeden elde edilen veriler SPSS 17 istatistik programı kullanılarak değerlendirilmiştir. Deneme verilerine varyans analizi uygulandıktan sonra, ortamlar arasındaki farklııklar Duncan testi $(P<0.05)$ ile belirlenmiştir. 


\section{BULGULAR VE TARTIŞMA}

\section{Yetiștirme Ortamının Kandil Özellikleri Üzerine Etkileri}

Oriental Lilium 'Siberia' yetiştiriciliğinde kullanılan farklı ortamlar kandil (Şekil 2) sayısını istatistiki olarak önemli derecede $(P<0.05)$ etkilemiştir. Kandil (çiçek tomurcuğu) sayısı ortalamaları yönünden perlit+torf, toprak(kontrol), torf+kum ve toprak+torf ortamları aynı grupta yer almış ve en yüksek değer (6.04 adet) perlit+torf ortamından, en düşük değer (3.66 adet) koyun gübresi+kum ortamından elde edilmiştir (Çizelge 2). Saygılı (2012) topraksız tarım koşullarında Lilium LA hybrids 'Ceb Dazzle' çeşidinde yaptığı çalışmada kandil sayılarını 3.64 adet ile 5.40 adet arasında bulmuştur. Tehranifar et al. (2011), Lilium 'Gironde' ve 'Cassandra' çeşitlerinde yaptıkları çalışmalarda sırası ile 4.6 adet ve 6.2 adet olarak bulmuşlar, en iyi sonucu (6.0 adet) $\% 40$ torf ve $\% 60$ perlit ortamından elde etmişlerdir. Kılıç (2013), 'Simplon' ve 'Rialto' Oriental zambak çeşitlerinde yaptığı çalışmada en iyi sonucu (6.47 adet) (1:2) perlit+torf karışımından elde etmiştir. Bu çalışmada perlit+torf ortamından elde edilen değer Saygılı (2012)'nin bulduğu en iyi değerin üstünde, en düşük değer ise bu değerler arasında yer almıştır. Tehranifar et al. (2011)'nın ve Kılıç (2013)'ın buldukları değerlere ise yakın sonuçlar bulunmuştur.

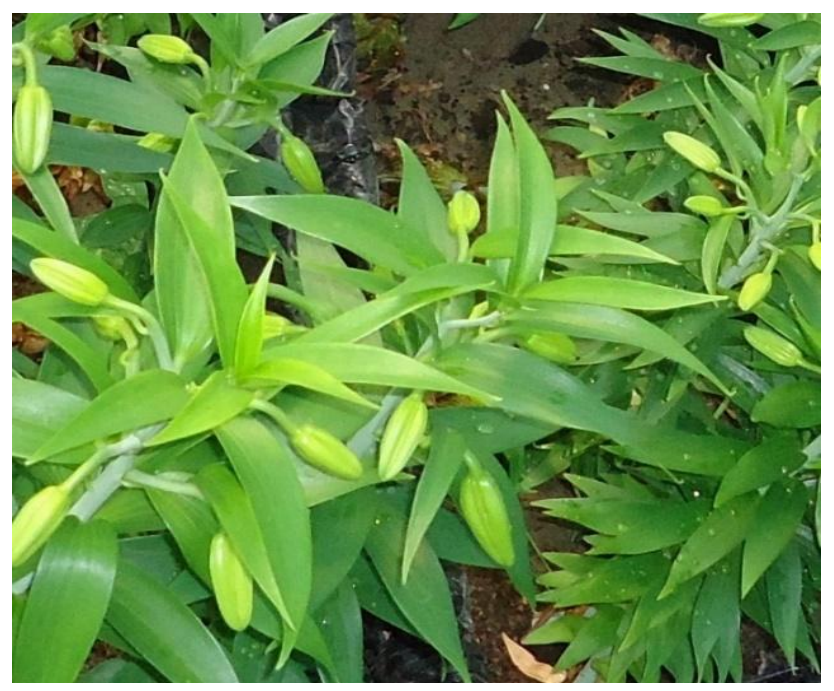

Şekil 2. Oriental Lilium 'Siberia' çeşidinde çiçek tomurcukları (kandil).

Figure 2. Flower buds on Oriental Lilium 'Siberia'.

Oriental Lilium 'Siberia' yetiştiriciliğinde kullanılan farklı ortam kandil uzunluğunu (tepal boyu) istatistiki olarak önemli derecede etkilemiştir. Kandil uzunluğu ortalamaları yönünden en yüksek değer $(10.41 \mathrm{~cm})$ torf+kum ortamından, en düşük değer $(9.15 \mathrm{~cm})$ ise koyun gübresi+kum ortam denemesinden alınmıştır (Çizelge 2). Saygılı (2012) Lilium LA hybrids 'Ceb Dazzle' çeşidinde yaptığı çalışmada kandil uzunluğu $10.33-11.30 \mathrm{~cm}$ arasında değiştiğini ifade etmişlerdir. Tehranifar et al. (2011), Lilium 'Gironde' (Asyatik) ve 'Cassandra' (Oriental) çeşitlerinde ortalama kandil uzunluklarını sırası ile $9.88 \mathrm{~cm}$ ve $7.91 \mathrm{~cm}$ olarak saptamışlardır. En yüksek değeri $(8.98 \mathrm{~cm})$ ise \%100 Hindistan cevizi lifinden elde ettiklerini bildirmişlerdir. Elde edilen değerler farklı çeşitlerde yapılan önceki çalışmalar (Saygılı 2012; Tehranifar et al., 2011) ile kıyaslandığı zaman yakın sonuçlar elde edildiği anlaşılmıştır.

Çizelge 2. Yetiştirme ortamının Oriental Lilium 'Siberia' çeşidinde ortalama kandil sayısı ve uzunluğu üzerine etkileri. Table 2. Effects of growing media of Oriental Lilium 'Siberia' on the average number and length of flower buds.

\begin{tabular}{lcc}
\hline $\begin{array}{l}\text { Yetiştirme } \\
\text { ortamı }\end{array}$ & $\begin{array}{c}\text { Kandil sayısı } \\
\text { (adet) }\end{array}$ & $\begin{array}{c}\text { Kandil } \\
\text { uzunluğu }(\mathbf{c m})\end{array}$ \\
\hline Toprak (kontrol) & $5.14^{\mathrm{a}}$ & $9.49^{\mathrm{bc}}$ \\
Toprak+torf & $5.53^{\mathrm{a}}$ & $9.82^{\mathrm{b}}$ \\
Perlit & $4.83^{\mathrm{ab}}$ & $8.84^{\mathrm{e}}$ \\
Perlit+torf & $6.04^{\mathrm{a}}$ & $9.55^{\mathrm{b}}$ \\
Torf+kum & $5.91^{\mathrm{a}}$ & $10.41^{\mathrm{a}}$ \\
Koyun gübresi+kum & $3.66^{\mathrm{c}}$ & $9.15^{\mathrm{cd}}$ \\
\hline
\end{tabular}

Aynı sütun üzerinde farklı harflerle gösterilen değerler arasında önemli fark vardır $(P<0.05)$.

\section{Yetiştirme Ortamının Çiçek Özellikleri Üzerine Etkileri}

Oriental Lilium 'Siberia' yetiştiriciliğinde kullanılan farklı ortamlar, kesme çiçeklerde en önemli kalite ölçütü (Çelikel 2014) olan, çiçek sap uzunluğunu istatistiki olarak önemli derecede $(P<0.05)$ etkilemiştir. Çiçek sap uzunluğu yönünden en yüksek $(55 \mathrm{~cm})$ torf+kum ortamından, en düşük $(28.83 \mathrm{~cm})$ ise koyun gübresi+kum ortamından alınmıştır (Çizelge 3). Özen et al. (2012) Lilium candidum üzerine yaptıkları çalışmada çiçek sapı uzunluğunu $43-150 \mathrm{~cm}$ arasında değişim göstermiş ve ortalama uzunluğu $87.82 \mathrm{~cm}$ olarak tespit etmişlerdir. Kahraman (2014) ise Lilium candidum üzerine yaptığı çalışmada en yüksek sap uzunluğunu $(64.64 \mathrm{~cm})$ kum ortamında ölçerken, en düşük $(47.63 \mathrm{~cm})$ ise zeolit ortamından elde etmiştir. Saygııı (2012) topraksız tarım koşullarında Lilium LA hybrids 'Ceb Dazzle' çeşidinde yaptığı çalışmada çiçek sap uzunlukları $69.67 \mathrm{~cm}$ ile $92.40 \mathrm{~cm}$ arasında değişim göstermiştir. Tehranifar et al. (2011), Lilium 'Gironde' ve 'Cassandra' çeşitlerindeki çalışmalarında çeşitlerin sap boyları sırası ile $50.70 \mathrm{~cm}$ ve $27.94 \mathrm{~cm}$ olarak saptanmıştır. En iyi sonuç ise $(44.9 \mathrm{~cm}) \% 40$ torf ve \%60 perlit ortamından elde edilmiştir. Ünye'de Oriental Lilium 'Siberia' çeşidinde yapılan bu çalışmada elde 
edilen çiçek sap boyu değerleri (Çizelge 3) önceki araştırmacıların verileri ile uyuşmaktadır. Ancak, dikimin ilkbahar yerine yazın yapılmış olmasının çiçek sap uzunluğunu olumsuz etkilemesi muhtemeldir.

Çizelge 3. Yetiştirme ortamının Oriental Lilium 'Siberia' çeşidinin ortalama çiçek sap boyu, sap çapı ve boğum sayısı üzerine etkileri.

Table 3. Effects of growing media of Oriental Lilium 'Siberia' on average flower stem length, stem diameter and number of nodium.

\begin{tabular}{lccc}
\hline $\begin{array}{l}\text { Yetiştirme } \\
\text { ortamı }\end{array}$ & $\begin{array}{c}\text { Çiçek sap } \\
\text { uzunluğu } \\
\text { (cm) }\end{array}$ & $\begin{array}{c}\text { Çiçek sap } \\
\text { çapı } \\
\text { (mm) }\end{array}$ & $\begin{array}{c}\text { Boğum } \\
\text { sayısı } \\
\text { (adet) }\end{array}$ \\
\hline Toprak (kontrol) & $47.78^{\mathrm{b}}$ & $12.02^{\mathrm{bc}}$ & $30.08^{\mathrm{ab}}$ \\
Toprak+torf & $49.95^{\mathrm{ab}}$ & $12.90^{\mathrm{a}}$ & $29.34^{\mathrm{bc}}$ \\
Perlit & $49.64^{\mathrm{b}}$ & $11.90^{\mathrm{c}}$ & $27.87^{\mathrm{c}}$ \\
Perlit+torf & $51.90^{\mathrm{ab}}$ & $12.49^{\mathrm{abc}}$ & $29.67^{\mathrm{bc}}$ \\
Torf+kum & $55.80^{\mathrm{a}}$ & $12.87^{\mathrm{ab}}$ & $31.80^{\mathrm{a}}$ \\
Koyun gübresi+kum & $28.83^{\mathrm{c}}$ & $10.41^{\mathrm{d}}$ & $25.75^{\mathrm{d}}$ \\
\hline
\end{tabular}

Aynı sütun üzerinde farklı harflerle gösterilen değerler arasındaki farklılık önemlidir $(P<0.05)$.

Oriental Lilium 'Siberia' yetiştiriciliğinde kullanılan farklı ortamlar çiçek sap çapını istatistiki olarak önemli derecede etkilemiştir. Çiçek sap çapı ortalamaları yönünden en yüksek değer (12.90 mm) torf+kum karışımından belirlenirken, en düşük değer ise 10.41 mm olarak koyun gübresi+kum ortamından elde edilmiştir (Çizelge 3). Topraksız tarım koşullarında Lilium LA hybrids 'Ceb Dazzle' çeşidinde çiçek sap çapı $8.30 \mathrm{~mm}-6.75 \mathrm{~mm}$ arasında değişim göstermiştir (Saygılı 2012). Kahraman (2015) yaptığı çalışmada çiçek sap çapını 7.03-7.33 mm olarak bulmuştur. Kılıç (2013) 'Simplo' ve 'Rialto' Oriental zambak çeşitlerinde yaptığı çalışmada en iyi sonucu $(6.56 \mathrm{~mm})$ torf ortamından elde etmiştir. Ünye'de Oriental Lilium 'Siberia' çeşidinde yapılan bu çalışmada çiçek sapları daha kalın bulunmuştur. Bu durumun ortam dışında, çeşit özelliğinden, iklim ve yetiştirme koşullarından kaynaklanması muhtemeldir.

Oriental Lilium 'Siberia' yetiştiriciliğinde kullanılan farklı ortamlar boğum sayısını istatistiki olarak önemli derecede $(p<0.05)$ etkilemiştir. Boğum sayısı ortalamaları yönünden en yüksek değer (31.80 adet) torf+kum ortamından, en düşük değer (25.75 adet) ise koyun gübresi+kum ortam denemesinden alınmıştır (Çizelge 3). Lilium LA hybrids 'Ceb Dazzle' çeşidinde boğum sayısının 53.13 ile 72.45 adet arasında değiştiği bildirilmiştir Saygılı (2012). Ünye'de Oriental Lilium 'Siberia' çeşidinde yapılan bu çalışmada saptanan değerler önceki çalışmaya (Saygılı 2012) göre oldukça düşük kalmıştır. Bu durumun diğer özelliklerde olduğu gibi ortam dışında, çeşit özelliğinden, iklim ve yetiştirme koşullarından kaynaklanması muhtemeldir.

\section{Yetiştirme Ortamının Yaprak Özellikleri Üzerine Etkileri}

Oriental Lilium 'Siberia' yetiştiriciliğinde kullanılan farklı ortamlar yaprak sayısını istatistiki olarak önemli derecede $(p<0.05)$ etkilemiştir. Yaprak sayısı ortalamaları yönünden en yüksek değer (57.73 adet) torf+kum ortamında, en düşük değer (33.1 adet) ise koyun gübresi+kum ortamında ölçülmüştür (Çizelge 4). Saygılı (2012) tarafından topraksız tarım koşullarında Lilium LA hybrids 'Ceb Dazzle' çeşidinde yapılan çalışmada yaprak sayısı 52-69 adet arasında değişmiştir. Tehranifar et al. (2011), Lilium 'Gironde' ve 'Cassandra' çeşitlerinde yaptıkları çalışmada çeşitlere göre yaprak sayısı sırası ile 48.8 adet ve 54.2 adet olarak saptanmıştır. En iyi sonucu (53.2 adet) ise \%40 torf ve \%60 perlit ortamından elde etmişlerdir. Ünye'de Oriental Lilium 'Siberia' çeşidinde elde ettiğimiz değerler araştırıcıların elde ettiği değerlere yakın bulunmuştur.

Çizelge 4. Yetiştirme ortamının Oriental Lilium 'Siberia' çeşidinin ortalama yaprak sayısı ve yaprak boyu üzerine etkileri.

Table 4. Effects of growing media of Oriental Lilium 'Siberia' on the average number and length of leaf.

\begin{tabular}{lcc}
\hline Yetiştirme ortamı & $\begin{array}{c}\text { Yaprak sayısı } \\
\text { (adet) }\end{array}$ & $\begin{array}{c}\text { Yaprak } \\
\text { uzunluğu (cm) }\end{array}$ \\
\hline Toprak (kontrol) & $50.64^{\mathrm{bc}}$ & 15.20 \\
Toprak+torf & $49.00^{\mathrm{cd}}$ & 11.55 \\
Perlit & $46.64^{\mathrm{d}}$ & 9.34 \\
Perlit+torf & $52.80^{\mathrm{b}}$ & 11.88 \\
Torf+kum & $57.73^{\mathrm{a}}$ & 7.97 \\
Koyun gübresi+kum & $33.16^{\mathrm{e}}$ & 6.50 \\
\hline
\end{tabular}

Aynı sütun üzerinde farklı harflerle gösterilen değerler arasında önemli fark vardır $(P<0.05)$.

Oriental Lilium 'Siberia' yetiştiriciliğinde kullanılan farklı yetiştirme ortamlarının yaprak uzunluğu üzerine etkisi istatistiki olarak önemsiz bulunmuştur. Yaprak uzunluğu ortalamaları yönünden en yüksek değer $(15.20 \mathrm{~cm})$ toprak (kontrol) ortamında, en düşük değer $(6.50 \mathrm{~cm})$ ise koyun gübresi+kum ortamında belirlenmiştir (Çizelge 4). Saygılı (2012) topraksız tarım koşullarında Lilium LA hybrids 'Ceb Dazzle' çeşidinde yaptığı çalışmada yaprak uzunlukları $8.69-11.62 \mathrm{~cm}$ arasında bulmuştur. Ünye'de Oriental Lilium 'Siberia' çeşidinde yapılan bu çalışmada koyun gübresi+kum ortamından elde edilen değerler bu değerlerin altında, kontrolde ise bu değerlerin üzerinde bir değer elde edilmiştir.

Oriental Lilium 'Siberia' yetiştiriciliğinde kullanılan farklı ortamlar çiçeklenme sürelerini $(P<0.05)$ etkilemiş̧ir. Illk çiçeklenme torf+kum, ikinci çiçeklenme toprak, üçüncü çiçeklenme perlit+torf, dördüncü 
çiçeklenme perlit ve son çiçeklenme ise koyun gübresi+kum ortamında görülmüştür. Tehranifar et al. (2011) tarafından, Lilium 'Gironde' ve 'Cassandra' çeşitlerinde çiçeklenme süreleri sırası ile 50.6 gün ve 59.0 gün olarak saptanmıştır. En erken (53.5 gün) çiçeklenmeyi ise $\% 40$ torf ve $\% 60$ perlit ortamından elde etmişlerdir. Katı ortam kültüründe yapılan araştırmalarda, çiçeklenme süresinin toprakta yapılan yetiştiriciliğe kıyasla daha erken olduğu belirlenmiştir. Benzer şekilde çalışmamızdan elde ettiğimiz değerlere bakıldığında, torf+kum kullanılan ortamdan elde ettiğimiz çiçeklenme süresinin kontrole göre daha erken olduğu belirlenmiştir.

\section{Yetiştirme Ortamının Soğan Verimi Üzerine Etkileri}

Oriental Lilium 'Siberia' yetiştiriciliğinde kullanılan farklı ortamlar yavru soğan sayısını istatistiki olarak önemli derecede $(P<0.05)$ etkilemiştir. Yavru soğan sayısı bakımından yetiştirme ortalamaları yönünden en yüksek değer (4.70 adet) torf+kum, en düşük değer ise (1.00 adet) koyun gübresi+kum uygulamasından alınmıştır (Çizelge 5). Saygılı (2012) topraksız tarım koşullarında Lilium LA hybrids 'Ceb Dazzle' çeşidinde yavru soğan sayısını 1.83-2.00 adet arasında değiştiğini ifade etmiştir. Bu değerleri Ünye'de Oriental Lilium 'Siberia' çeşidinde yapılan çalışmada elde edilen değerler ile kıyasladığımız zaman, torf+kum ortamında daha yüksek, koyun gübresi+kum ortamında ise bu değerlerin altında kalmıştır. Koyun gübresi kullanılan ortam beklendiği üzere, yavru soğan sayısını düşürürken iriliğini artırmıştır (Çizelge 5).

Çizelge 5. Yetiştirme ortamının Oriental Lilium 'Siberia' çeşidinin ortalama yavru soğan verimi üzerine etkileri.

Table 5. Effects of growing media of Oriental Lilium 'Siberia' on the average yield of bulblet formation.

\begin{tabular}{lccc}
\hline $\begin{array}{l}\text { Yetiştirme } \\
\text { ortamı }\end{array}$ & $\begin{array}{c}\text { Soğan eni } \\
(\mathbf{m m})\end{array}$ & $\begin{array}{c}\text { Soğan boyu } \\
(\mathbf{m m})\end{array}$ & $\begin{array}{c}\text { Soğan } \\
\text { adedi }\end{array}$ \\
\hline Toprak (kontrol) & $8.62^{\mathrm{b}}$ & 12.35 & $2.66^{\mathrm{abc}}$ \\
Toprak+torf & $10.30^{\mathrm{b}}$ & 14.02 & $3.14^{\mathrm{ab}}$ \\
Perlit & $8.99^{\mathrm{b}}$ & 12.15 & $2.81^{\mathrm{abc}}$ \\
Perlit+torf & $8.45^{\mathrm{b}}$ & 13.33 & $2.50^{\mathrm{bc}}$ \\
Torf+kum & $8.00^{\mathrm{b}}$ & 12.33 & $4.70^{\mathrm{a}}$ \\
Koyun gübresi+kum & $13.85^{\mathrm{a}}$ & 14.91 & $1.00^{\mathrm{c}}$ \\
\hline
\end{tabular}

Aynı sütun üzerinde farklı harflerle gösterilen değerler arasında önemli fark vardır $(P<0.05)$.

Ana soğanların oluşturduğu yavru soğanlar ile ilgili incelenen bir diğer kriter olan soğanların en ve boyları incelendiğinde, farklı ortamların yavru soğanların enini istatistiki olarak önemli derecede $(p<0.05)$ etkilediği saptanmıştır. Çiçeklenme sonrası sökülen ana soğan üzerinde oluşan yavru soğanların genişliği 8.45 ile $13.85 \mathrm{~mm}$ arasında değişmiştir. Yavru soğanların eni koyun gübresi+kum ortamında en yüksek, torf+kum ortamında ise en düşük olmuştur (Çizelge 5). Saygılı (2012) Lilium LA hybrids 'Ceb Dazzle' çeşidinde yavru soğan enini 10.11-14.34 mm arasında bulmuştur. Kandemir et al. (2013) sebzeler üzerinde yürüttükleri çalışmada en yüksek fide çapı ve toplam fide kuru ağırlığı hayvan gübresi ve toprak karışımından elde etmişlerdir. Ünye'de Oriental Lilium 'Siberia' çeşidinde yapılan bu çalışmada benzer şekilde koyun gübresi kullanılan ortamdan en yüksek değerler elde edilmiştir.

Yavru soğan boyu $(\mathrm{mm})$ açısından ise elde edilen sonuçlar incelendiğinde farklı ortamların yavru soğanların boyunu istatistiki olarak etkilemediği ortaya çıkmıştır. Çiçeklenme sonrası sökülen ana soğan üzerinde oluşan yavru soğanların boyu 12.15 ile $14.91 \mathrm{~mm}$ arasında değişmiştir. Yavru soğan boyu en fazla koyun gübresi+kum (14.91 mm) ortamından, en düşük ise perlit (12.15 mm) ortamından elde edilmiştir (Çizelge 5). Saygılı (2012) Lilium LA hybrids 'Ceb Dazzle' çeşidinde yavru soğan boyunu 10.90 ile 14.54 $\mathrm{mm}$ arasında bulmuştur. Ünye'de Oriental Lilium 'Siberia' çeşidinde yapılan bu çalışmada elde edilen değerler Saygılı (2012) 'nin bulduğu değerlere yakın olarak bulunmuştur.

\section{SONUÇ}

Bu çalışma Oriental Lilium 'Siberia' yetiştiriciliğinde üreticiler için ulaşılabilir ve düşük maliyet ile yetiştiricilik yapabilecekleri en iyi ortamı belirlemek için yapılmıştır. Farklı ortamlar çeşitli çiçek özelliklerini ve yavru soğan verimini önemli derecede $(p<0.05)$ etkilemiştir. Yapılan ölçümlere göre farklı sonuçlar olmasına karşın, genel olarak en etkili büyüme ortamı torf+kum karışımından elde edilirken bunu perlit+torf ve toprak+torf ortamları izlemiştir. Kullanılan ortamlar içinde torf+kum karışımının kesme çiçek kalitesinde en önemli ölçütlerden (Çelikel 2014) olan çiçek sap boyunu artırdığı saptanmıştır. Ancak bölgede süs bitkileri yetiştiriciliğinin geliştirilmesi amacıyla uygun yetiştirme ortamlarının belirlenmesi üzerine farklı tür ve çeşitlerde daha ayrıntılı çalışmaların geliştirilerek devam etmesi önerilmektedir.

\section{KAYNAKLAR}

Çelikel FG., Dodge LL and Reid MS., 2002 Efficiacy of 1-MCP and promalin for extending the postharvest life of Oriental lilies (Lilium x 'Mona Lisa' and 'Stargazer'). Scientia Horticulturae, 93: 149-155.

Çelikel FG., 2014. Kesme Çiçekçilik Ders Notları. Ondokuz Mayıs Üniversitesi Ziraat Fakültesi, Samsun.

Hussain R., Younis A., Riaz A., Tariq U., Ali S., Ali A and Raza S., 2016. Evaluating sustainable and 
environment friendly substrates for quality production of potted Caladium. International Journal of Recycling of Organic Waste in Agriculture, 6: 13-21.

Johannes A.,1996. Lily plant named 'Siberia'. https://www.google.com/patents/. [Access: April 5, 2017].

Kahraman Ö., 2014. Sera koşullarında farklı katı ortam kültürlerinin Lilium candidum yetiştiriciliği üzerine etkisi. Gaziosmanpaşa Üniversitesi Ziraat Fakültesi Dergisi, 31: 68-72.

Kandemir D., Özer H., Özkaraman F and Uzun S., 2013. The effect of different seed sowing media on the quality of cucumber seedlings. The European Journal of Plant Science and Biotechnology, 7: 66-69.

Kılıç T., 2013. Örtü altında farklı yetiştirme ortamlarının bazı oriental zambak (lilium spp.) çeşitlerinin kesme çiçek performansı üzerine etkileri. Yüksek Lisans Tezi (Basılmamış), Ankara Üniversitesi Fen Bilimleri Enstitüsü, Ankara.

Klasman R., Moreira H., Di B and Adalberto H., 2002. Asiatic hybrids Lilium sp. growth under three soil amendments. Revista de la Facultad de Agronomía, 22: 79-83.

Maloupa E., Mitsios I., Martinez PF and Bladenopoulou S., 1993. Study of substrates use in gerbera soilless culture grown in plastic greenhouses. Acta Horticulturae, 323: 139-144.

Okanlawon SO., Babatunde KM., Salau MA., Adekanmbi OA and Jmoh AR., 2016. Effects of different growth media on propagation of horticultural plant, Mussaenda philippica (Queen of Philippines). International Journal of Current Research in Biosciences and Plant Biology, 3: 4-10.

Saygılı L., 2012. Lilyum yetiştiriciliğinde farklı agregatların ve besin solüsyonlarının kullanım olanakları. Yüksek Lisans Tezi (Basılmamış), Adnan Menderes Üniversitesi Fen Bilimleri Enstitüsü, Aydın.

Tehranifar A., Selahvarzi Y and Alizadeh B., 2011. Effect of different growing media on growth and development of two Lilium (Oriental and Asiatic Hybrids) types in soilless conditions. II International Symposium on the Genus Lilium, Acta Horticulturae, 900: 139-141.

Treder J., 2008. The effects of cocopeat and fertilization on the growth and flowering of Oriental lily 'Star Gazer'. Journal of Fruit and Ornamental Plant Research, 16: 361 370.

TÜiK 2016. Bitkisel üretim istatistikleri. https://biruni.tuik. gov.tr/bitkiselapp/bitkisel.zul. [Erişim: 5 Haziran 2017].

Yılmaz R ve Korkut A., 1998. Zambak (Lilium L.) Yetiştiriciliğinde Değişik Harç Kullanımının Çiçeklenmeye Etkileri. I Ulusal Süs Bitkileri Kongresi, 6-9 Ekim, Yalova. 